\title{
Physical soil quality indicators for monitoring British soils
}

\author{
Ron Corstanje $^{1}$, Theresa G. Mercer ${ }^{2}$, Jane R. Rickson ${ }^{1}$, Lynda K. Deeks ${ }^{1}$, Paul Newell-Price ${ }^{3}$, Ian Holman ${ }^{4}$, \\ Cedric Kechavarsi ${ }^{5}$, and Toby W. Waine ${ }^{1}$ \\ ${ }^{1}$ Cranfield Soil and Agrifood Institute, School of Water, Energy and Environment (SWEE), Cranfield University, \\ Bedfordshire, MK43 0AL, UK \\ ${ }^{2}$ Cranfield Institute for Resilient Futures, School of Water, Energy and Environment (SWEE), Cranfield University, \\ Bedfordshire, MK43 0AL, UK \\ ${ }^{3}$ ADAS Gleadthorpe, Meden Vale, Mansfield, Notts., NG20 9PF, UK \\ ${ }^{4}$ Cranfield Water Science Institute, School of Water, Energy and Environment (SWEE), Cranfield University, \\ Bedfordshire, MK43 0AL, UK \\ ${ }^{5}$ Department of Engineering, University of Cambridge, University of Cambridge, Trumpington Street, \\ Cambridge, CB2 1PZ, UK
}

Correspondence to: Theresa G. Mercer (t.mercer@cranfield.ac.uk)

Received: 8 November 2016 - Discussion started: 18 November 2016

Revised: 28 June 2017 - Accepted: 12 July 2017 - Published: 28 September 2017

\begin{abstract}
Soil condition or quality determines its ability to deliver a range of functions that support ecosystem services, human health and wellbeing. The increasing policy imperative to implement successful soil monitoring programmes has resulted in the demand for reliable soil quality indicators (SQIs) for physical, biological and chemical soil properties. The selection of these indicators needs to ensure that they are sensitive and responsive to pressure and change, e.g. they change across space and time in relation to natural perturbations and land management practices. Using a logical sieve approach based on key policy-related soil functions, this research assessed whether physical soil properties can be used to indicate the quality of British soils in terms of their capacity to deliver ecosystem goods and services. The resultant prioritised list of physical SQIs was tested for robustness, spatial and temporal variability, and expected rate of change using statistical analysis and modelling. Seven SQIs were prioritised: soil packing density, soil water retention characteristics, aggregate stability, rate of soil erosion, depth of soil, soil structure (assessed by visual soil evaluation) and soil sealing. These all have direct relevance to current and likely future soil and environmental policy and are appropriate for implementation in soil monitoring programmes.
\end{abstract}

\section{Introduction}

In recent years soil quality and its measurement have increasingly been based on soil functions (Loveland and Thompson, 2002; Ritz et al., 2009; Rosa, 2005). These functions determine the ability of a soil to deliver and support ecosystem goods and services, which have been linked to human health and wellbeing, but are often difficult to quantify. Soils are typically recognised for their role in provisioning goods such as building materials, fresh water, fuel, fibre and food (Robinson et al., 2013). Soils also interact with other environmental components (air and water) and provide a platform for infrastructure. The ecosystem services that rely on these functions include regulation of climate and hydrology, contaminant transformation, biocontrol of plant pathogens and parasites (Sylvain and Wall, 2011), and water filtration/runoff reduction/purification (Breure et al., 2012). Supporting services provided by soils include soil formation, soil fertility, biogeochemical cycling ( $\mathrm{C}$ storage and nutrient cycling), decomposition of organic materials and plant available water. A number of cultural services are also supported such as recreational surfaces (Robinson et al., 2013) and heritage services including preserving historic artefacts, burial grounds and non-monetary values, such as containing information of events that have occurred in historical and geological timescales (Costantini and L'Abate, 2009). There are 
a number of databases and protection strategies in place for soils with cultural heritage (otherwise known as pedosites, geosites and geoparks) (Serrano and Ruiz-Flaño, 2007; UNESCO, 2016). In summary, soil-derived goods are tangible and include the food, fibre and fodder produced from soil. Soil-derived services are intangible and examples include water and climate change regulation through carbon sequestration.

For many soil ecosystem services, there are significant gaps in the valuation literature, especially related to soil regulation and formation, nutrient regulation and water regulation (Costanza et al., 2006; Jonsson and Davidsdottir, 2016). Soils deliver both economic and ecological benefits, the latter being less amenable to quantification and assessment. Better understanding of soil properties and associated functions will provide information for improved valuation of the services and goods delivered by soil.

However, the ability of soil to function and deliver these essential goods and services can be threatened by soil degradation processes. These include soil erosion, compaction, loss of organic matter content, loss of biodiversity, soil surface sealing, acidification and salinisation (European Commission, 2006). These processes can be natural and/or caused by human actions, such as using land beyond its inherent capability. Soil degradation processes result in changes in soil physical, biological and chemical properties, so affecting soil functions and soil quality.

In order to measure soil quality and functions, soil quality indicators are commonly used. Indicators of soil quality are required for environmental monitoring/reporting and provide the basis for many soil protection policies and monitoring programmes (Pulleman et al., 2012). Indicators help assess human and natural impacts on soils, including degradation processes and identify the effectiveness (or otherwise) of sustainable land management practices (Doran and Parkin, 1994; Karlen and Stott, 1994; Schipper and Sparling, 2000). They have also been used to evaluate the effectiveness of restoration strategies (Costantini et al., 2016). In order to assess soil quality, a combined approach is required in which the soil's biological, chemical and physical attributes and their interactions are assessed (Bone et al., 2010; Seybold et al., 1998). In this respect, monitoring is defined as a method to determine the quality and condition of the soil environment over space and time. This is measured by determining actual values of the attributes of interest.

There have been a few studies that have discussed and attempted to prioritise the most appropriate soil quality indicators (SQIs) for biological (Masto et al., 2015; Pulleman et al., 2012; Ritz et al., 2009) and physico-chemical indicators (Arshad and Coen, 1992; Asensio et al., 2013; Karlen and Stott, 1994; Masto et al., 2015; Rickson et al., 2012). This study focusses on a systematic process of selection for physical SQIs and then explores their potential for use in national monitoring schemes (e.g. England and Wales) (Loveland and Thompson, 2002; Merrington et al., 2006). In par- ticular, practical aspects such as sampling design and size, the use of proxies and pedotransfer functions, and the application of sensor technology are explored.

The role or function of a soil system can be defined differently, depending on the stakeholder/user groups and their specific objectives (e.g. whether they are interested in the production, regulation or cultural services of soil) (Rickson et al., 2012). As such, indicators are usually selected on the basis of the function(s) of interest, and observed and measured to infer the capability of a soil to perform that particular function (Bone et al., 2010; Ditzler and Tugel, 2002; Doran and Parkin, 1994). Once selected, effective SQIs need to meet the following criteria:

- be meaningful, interpretable and sensitive (and measurable) to natural and human-induced pressures and change (Burger and Kelting, 1999; Loveland and Thompson, 2002);

- reflect the desired condition or end point for a particular soil and/or land use and/or function (Loveland and Thompson, 2002);

- be relatively cheap, practical and simple to monitor (Loveland and Thompson, 2002);

- be responsive to corrective/management measures (Burger and Kelting, 1999);

- be applicable over large areas and different soils/land use types (Burger and Kelting, 1999);

- be capable of providing continuous assessment over long timescales (Burger and Kelting, 1999).

Selected physical SQIs need to be sensitive to pressure and able to reflect change in soil quality status (the capacity of the soil to function) at any given location and time (Burger and Kelting, 1999; Loveland and Thompson, 2002; Rickson et al., 2012). As such, an effective physical SQI would need to detect "meaningful change" in a given soil property and associated function(s) and be responsive to this change in the light of expected changes in soil quality. In other words, does the physical SQI change sufficiently that it can be detected, and is this change indicative of a significant loss/gain in soil quality? In order to evaluate the effectiveness of the indicator, the criteria for what constitutes a "meaningful change" need to be set.

In some instances, where the indicator itself may drive the change (for example the effect of bulk density on crop growth), "meaningful change" may be as simple as ascertaining the SQI value at a particular location and comparing this to a critical value or target value or range. This approach is taken by Merrington et al. (2006) and whilst simple in its approach, it does not capture the dynamic relationships between SQI and soil functions. These relationships may differ between soil functions, land uses and soil types (Jones, 
1983). As such, there needs to be a focus on the dynamic relationships between soil functions and SQIs: however, information in the literature is sparse. Physical SQIs also need to be meaningful in terms of the soil processes that they represent. A change in the SQI needs to relate to a change in the processes that are taking place in the soil and therefore how the soil functions. For example, a change (increase) in bulk density would result in a change in processes operating in the soil (e.g. restriction to root elongation) and therefore a change in soil function (reduced crop yield).

Soil properties are spatially and temporally variable as a result of land use and management, parent material and climate. For example, there are over 1800 soils in Britain alone. Geological diversity means that these soils range from porous sands to impermeable clays. They include upland and lowland peat areas, surface and ground water gleys, shallow calcareous lithomorphic soils and free-draining brown soils. They range from acid to alkaline. Some soils are directly related to the parent material below them and others are unrelated, having been previously transported by wind, water and glacial action. Soil depths range from shallow $(<10 \mathrm{~cm})$, typically over chalk, to deeper soils ( $>150 \mathrm{~cm}$ ), typically sandy silt loam, silt loam to silty clay loam soils. The soils in lowland Britain have largely been modified by anthropogenic activity, as most are intensively managed for agricultural production and have therefore been affected by tillage and some by artificial drainage.

Inevitably, this variability introduces "noise" into the signal response (signal: noise, i.e. meaningful change) in two ways. Firstly, there is the consideration of the spatial unit over which the soil quality is assessed. The spatial variability within this unit (e.g. plot, field, farm, catchment, national scale) will introduce variability to the SQI, irrespective of whether there are any changes in soil function(s). Secondly, there is the consideration of the impact of a particular land management practice on the effectiveness of a SQI to indicate soil quality.

Based on the above criteria and considerations, it has been argued that it may not be possible to achieve a single, affordable, workable soil quality index (Sojka and Upchurch, 1999) or a consensus on a standardised methodology which would be appropriate across different soil and land use types (Karlen and Stott, 1994). Furthermore, soils can frequently perform several functions simultaneously, although these can be diverse and often conflicting, but they must still be taken into account (Bone et al., 2010; Schoenholtz et al., 2000).

The ultimate aim of this study is to inform the design and implementation of a national-scale soil monitoring programme. This will centre on the identification of a number of meaningful indicators of physical soil quality that detect and reflect changes in soil properties over space and time, the associated changes in soil functions, and the goods and services delivered by soil. The study uses a multi-stage approach in the selection and prioritisation of physical SQIs that meet the required criteria and conditions outlined above. It consists of a systematic review and selection procedure, followed by assessment of the selected SQIs and how they could be best applied in a national-scale monitoring programme. The final priority list should indicate the soil's capacity to deliver ecosystem goods/services and is therefore indicative of soil quality.

\section{Methodology}

The process of physical SQI selection takes a multi-stage approach as outlined in Fig. 1. In the first stage, potential physical SQIs were identified from the available literature, including those defined by Loveland and Thompson (2002) and Merrington et al. (2006). Other physical SQIs (and the methods used to measure them) that had not been considered previously were also included to produce an up-to-date list. In the second stage, the candidate physical SQIs were prioritised using a logical sieve (Ritz et al., 2009) and a scenariobased approach. Here, the logical sieve was interrogated by running three scenarios based on typical priorities of different stakeholders, by applying weightings to the scoring system used to prioritise SQIs. As such, the approach was used to prioritise a specific soil function or degradation process of interest (Rickson et al., 2012).

Finally, the priority physical SQIs were tested for robustness (statistical reliability and accuracy as well as practicability), spatial and temporal variability, and expected rate of change using statistical analysis and modelling. This involves determining appropriate sample numbers for defining meaningful change, as well as proxy methods that can be used to make the physical SQI measurements operational and feasible. For example, where measurement and monitoring of a standard physical SQI may be time or resource intensive in a large-scale monitoring programme, a proxy that is easier and cheaper to measure may exist that could make that physical SQI feasible for inclusion into such a programme.

\subsection{Identification of potentially meaningful physical SQIs}

The identified physical SQIs were derived from the literature with consideration of recent scientific advances and developments in soil policy. Loveland and Thompson (2002) identified 22 direct and 4 indirect physical SQIs. Direct indicators refer to those that are associated directly with a soil function, whereas indirect indicators refer to those that are indirectly related to a soil function. Merrington et al. (2006) give the example of soil water storage following rainfall as a direct indicator, whereas a catchment hydrograph is an example of an indirect indicator of rainfall interception and water storage by soils. Merrington et al. (2006) identified 30 direct and 4 indirect physical indicators. Collating the physical SQIs identified in the literature gave a total of 42 indicators. A list of these is provided in Table S1 in the Supplement. 


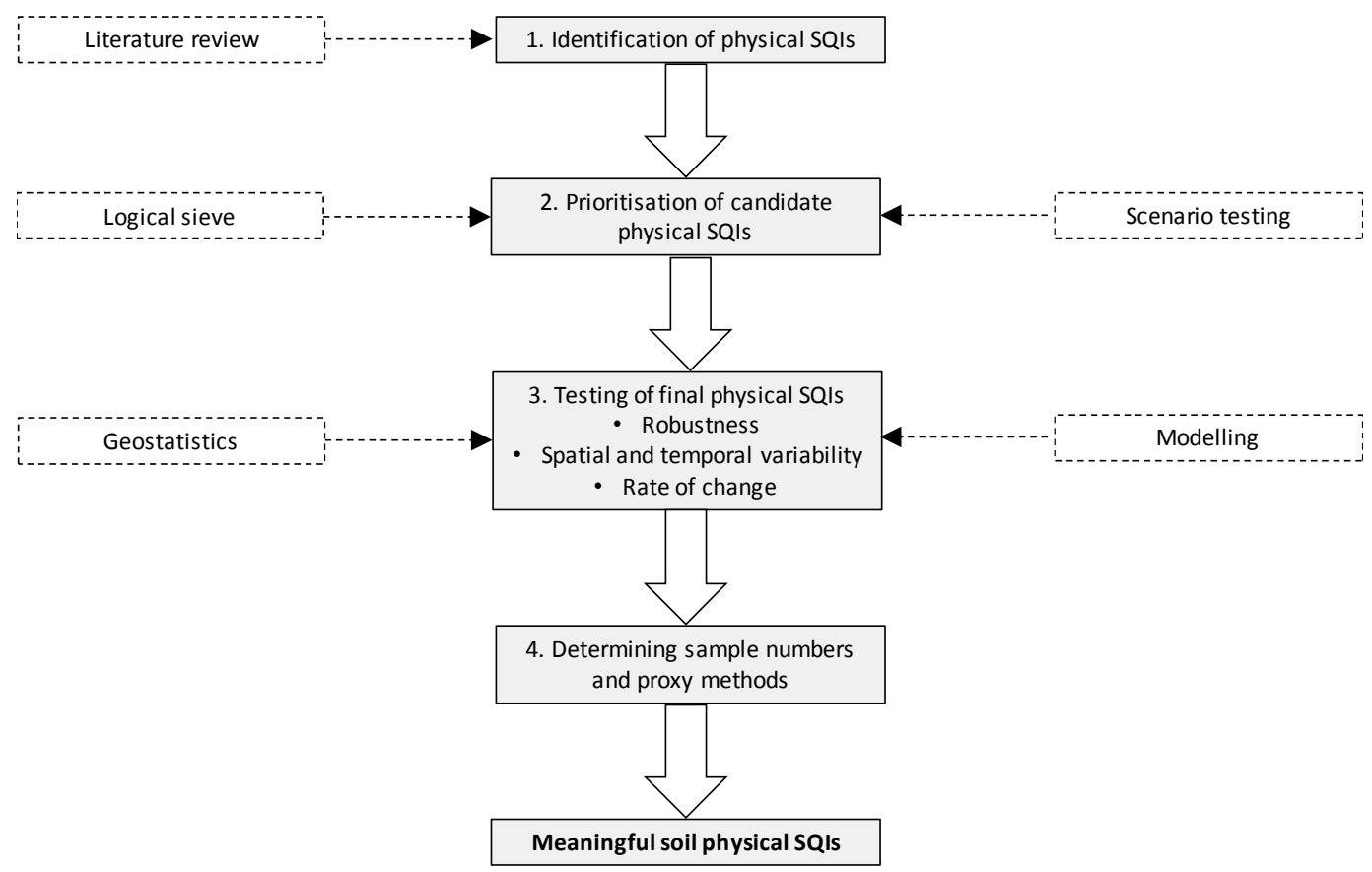

Figure 1. Multi-stage approach taken in the selection of meaningful physical soil quality indicators (SQIs).

Where an indicator could be measured using alternative techniques/approaches, sub-categories reflecting this were created, ensuring that the indicator and its different measurement methods were scrutinised by the logical sieve.

\subsection{Prioritisation of candidate physical SQIs}

The 42 physical SQIs were evaluated in terms of the following criteria:

Criterion 1 Soil function: does the candidate SQI reflect all soil function(s)? In this case, the four main functions, as described in the Millennium Ecosystem Assessment (Millennium Ecosystem Assessment, 2005), were used (i.e. provisioning, regulating, cultural and supporting).

Criterion 2 Land use: does the candidate SQI apply to all land uses found nationally? The range of land uses considered was based on the Centre for Ecology and Hydrology's land cover map (Morton et al., 2011) that also reflected differences in land use resulting from differences in land management practices (e.g. cultivations on arable land as opposed to pasture).

Criterion 3 Soil degradation process: can the candidate SQI express the impacts of soil degradation processes? This refers to the range and representation that each physical SQI gives to the main soil degradation processes as identified in the Thematic Strategy for Soil Protection (European Commission, 2006, Table S4) was considered. This approach captures whether the SQIs reflect the effect of potential degradation threats on soil functions.

Criterion 4 Challenge criteria: does the candidate SQI meet the challenge criteria used by Merrington et al. (2006)? These challenge criteria were developed for a nationalscale soil monitoring scheme and were integrated with criteria used to identify the inverse of soil quality indicators from the ENVASSO project (Huber et al., 2008). For example, are the measurements of the indicator practicable? Can the indicator be measured cost effectively? Is the indicator policy relevant?

Each of these criteria categories (and constituent factors) was considered separately and each of the physical SQIs was scored numerically, with weighting factors using the approach outlined by Ritz et al. (2009). The criteria are presented in Tables S2-S5 in the Supplement; the methodology for weighting, scoring and ranking in Methods S6; and an example of the logical sieve assessment in Table S7. Three scenarios were run to test the logical sieve.

Scenario 1 involved no weightings applied (all factors are equally important). For example, when considering Category 1 (soil functions category), all soil functions (provisioning, regulating, cultural and supporting) are equally important. In scenario 2, a higher priority was applied to the provisioning and regulation soil functions (factors). These two soil functions were selected as they are considered high priorities in current soil policy as highlighted in the Natural Environment White Paper "The natural choice: securing the value of nature" (DEFRA, 2011a), the Soils Evidence Plan (DEFRA, 
$2011 b$ ). Scenario 3 used a weighting factor to normalise values across all categories. As such, differences in the number of factors in each category would not affect the outcome (e.g. Category 1 (soil function) includes four factors to consider, Category 2 (land use) has seven factors to consider, and so on).

These scenarios represent the types of questions that may be asked by different stakeholder groups. The results from the three scenarios (top $25 \%$ cumulative scores, as well as any of the physical SQIs that survived the sieving process by scoring $>0$ in all factors of all categories) resulted in 18 candidate physical SQIs (from the original 42; Table S1; Methods S8). These "short-listed" indicators were further filtered by taking a more "numerical" approach, i.e. are data available to test the robustness of the candidate SQIs through statistical/modelling analysis? Also, the remaining SQIs were rationalised in terms of duplications, overlaps/double counting and linkages. Selection was also made on the basis of whether there was scientific evidence regarding the following:

1. What is the candidate SQI indicative of (i.e. what function is being degraded)?

2. What it is responsive to? How responsive is it (i.e. sensitivity, responsiveness)?

3. What factors may mitigate or accentuate the response (e.g. soil type, land use)?

4. Is this indicator a first-order indicator (i.e. the SQI is a direct measure of the change in soil quality) or a second, third-, etc. order indicator (i.e. the change in the SQI is measured indirectly, e.g. by remote sensing)?

5. Are there existing or suspected data holdings for the indicator?

6. How is it measured?

7. What sampling support does it need?

8. What is the sampling intensity required?

As a result of this process, seven physical SQIs were selected for further analysis:

- soil packing density/bulk density,

- soil water retention characteristics,

- soil sealing,

- depth of soil,

- visual soil evaluation,

- rate of soil erosion,

- soil aggregate stability.

\subsection{Assessment of priority physical SQIs}

These final physical SQIs were tested for uncertainty in their measurement, the spatial and temporal variability in the indicator (as given by observed distributions), and the expected rate of change (for a given soil function in light of expected changes in soil quality) in the indicator. For each SQI, the following points were addressed:

- whether the SQI could be directly related to soil functions,

- what constitutes meaningful change in the SQI by determining the relationships between the SQI (and how it changes) and soil processes,

- the spatial variability of the SQI and the implications for sampling using spatial statistics and power analyses.

\subsection{Statistical analyses and modelling approach}

The type of analyses conducted on the SQIs depended on the type of soils data available. Where full data were available, quantitative methods such as power analysis or pedo-transfer functions were used. Statistical power is the probability that a specific difference will be detected at a specified level of confidence. It allows the determination of a sample size required to detect an effect of a given size with a degree of confidence (Rickson et al., 2012). Otherwise analysis was carried out (semi)qualitatively (e.g. using remote sensing) or qualitatively (where no data exist). Three of the selected priority physical SQIs will be discussed in this paper, as sufficient monitoring data were readily available for each (Table 1). This allowed geostatistical analysis and application of pedotransfer functions, including evaluations based on quantitative or semi-quantitative methods.

Where there was substantive quantity of data (e.g. packing density), we explored the sampling intensity required to detect a change in the SQI. In other words, for the SQI to be effective as an indicator, it needs to be sensitive to changes in soil quality, and sufficiently responsive to be detectable above the natural variability of the soil (meaningful change) without requiring an impractical number of samples to determine this change. We estimated the natural variability of a particular property in two ways: (i) through a natural stratification by land use and soil types and (ii) through geostatistics (see Methods S9), where we used block kriging to estimate the within block variance of blocks sized 5, 10, 25 and $50 \mathrm{~km}^{2}$, roughly approximating management units of increasing size (e.g. field, farm, landscape).

Where the particular property is obtained from complex analytical methods, such as soil water retention characteristics, we explored the use of pedotransfer functions, in particular a multiple regression model and multiple additive regression splines, which are described in Methods S10. 
Table 1. Datasets and analyses for selected physical SQIs.

\begin{tabular}{|c|c|c|c|}
\hline Physical SQI & Available datasets & Data & Analyses \\
\hline \multirow[t]{3}{*}{ Packing density } & $\begin{array}{l}\text { LandIS (Soil Survey of England } \\
\text { and Wales) http://www.landis. } \\
\text { org.uk/ }\end{array}$ & $\begin{array}{l}1250 \text { measurement of bulk } \\
\text { density and clay content } \\
\text { averaged over soil profiles }\end{array}$ & \multirow[t]{3}{*}{$\begin{array}{l}\text { - Power analysis } \\
\text { - Spatial statistics }\end{array}$} \\
\hline & $\begin{array}{l}\text { ADAS (DEFRA } \\
\text { project BD5001) } \\
\text { (Price et al., 2012) }\end{array}$ & $\begin{array}{l}300 \text { short-range measurements } \\
\text { of bulk density }\end{array}$ & \\
\hline & $\begin{array}{l}\text { DEFRA project SP1606 } \\
\text { (Graves et al., 2011) }\end{array}$ & $\begin{array}{l}\text { Supra-classifications of } \\
\text { soil-land use combinations }\end{array}$ & \\
\hline $\begin{array}{l}\text { Soil water retention } \\
\text { characteristics }\end{array}$ & $\begin{array}{l}\text { LandIS (Soil Survey of England } \\
\text { and Wales) } \\
\text { http://www.landis.org.uk/ }\end{array}$ & $\begin{array}{l}2480 \text { soil profiles with soil } \\
\text { water retention values } \\
\text { Volumetric moisture content } \\
\text { measured at pressure heads of } \\
0.5,1,4,20 \text { and } 150 \mathrm{~m} \\
\text { Total porosity }(\%)\end{array}$ & $\begin{array}{l}\text { - Hydrological modelling } \\
\text { - Pedo-transfer functions }\end{array}$ \\
\hline Soil sealing & Remote sensing data & $\begin{array}{l}\text { Discussion of available } \\
\text { methods to measure and } \\
\text { monitor soil sealing }\end{array}$ & $\begin{array}{l}\text { - } n \text { considerations of pixel size } \\
\text { and appropriate satellite images } \\
\text { for determination of sealing of } \\
\text { soil and degree of } \\
\text { imperviousness }\end{array}$ \\
\hline
\end{tabular}

\section{Results and discussion}

\subsection{Packing density}

Packing density is a measure of soil porosity and an indirect measure of soil functions such as water regulation, biomass production and habitat support. It also provides a good estimate of soil compaction due to reduced total porosity. Compaction is generally associated with land degradation (the inverse of soil quality, Huber et al., 2008) and can result in decreases in water holding capacity, water infiltration, microbial functions and biogeochemical cycling (Edmondson et al., 2011; Gregory et al., 2015a). It is derived by measuring dry bulk density (BD) modified by clay content (C) and is a very useful parameter for spatial interpretations that require a measure of the compactive state of soils (Jones et al., 2003).

Bulk density (from which packing density is derived) is most commonly measured using a Kopecky ring. This method is easy, convenient and cheap, but results can be unrepresentative over large spatial areas due to the small diameter of the ring or cylinder, and depth of measurement (usually $5 \mathrm{~cm}$ ). A number of proxies exist that overcome some of the issues regarding sampling effort using the traditional Kopecky ring method. These allow a higher resolution of measurements (1500-2500 samples) per hectare over larger areas and include online (mobile) and non-mobile systems (Rickson et al., 2012). The methods used require multiple sensors and advanced techniques for data analysis (Mouazen and Ramon, 2006) such as a combination of visual and near-infrared (vis-NIR) measurements, combined with Theta probe determinations for soil moisture or with soil resistance (penetrometer measurements) and vis-NIR measurements to determine BD (and thus PD, when combined with clay content).

Measurements of packing density (PD) can detect relatively large changes in soil physical properties. PD has been used to detect differences in soil compaction between different management practices, such as contrasting tillage systems (da Silva et al., 2001; Dam et al., 2005). For example, in no-till systems, BD can be $10 \%$ higher compared to conventional tillage systems, particularly in the $0-10 \mathrm{~cm}$ layer (Dam et al., 2005).

The power analysis based on land use by soil strata from national data (Fig. 2) clearly demonstrates the trade-off between the sample size required to detect a meaningful change in packing density (i.e. a change that impacts on soil functioning). Approximate sample sizes for a national monitoring programme can be determined based on expense and desired power. In terms of sampling effort, this suggests that a different sampling regime would be required for different geographical areas to ensure statistical robustness, taking into account the different land use/soil and climate combinations.

The influence of spatial scales on sample size was calculated using a model-based approach where the variation of different regions (size of spatial unit) was obtained from a variogram in Methods S9. The sample size needed if a change is to be determined over different spatial scales areas (i.e. field: 5 and $10 \mathrm{~km}^{2}$; farm: $25 \mathrm{~km}^{2}$; and landscape level: 


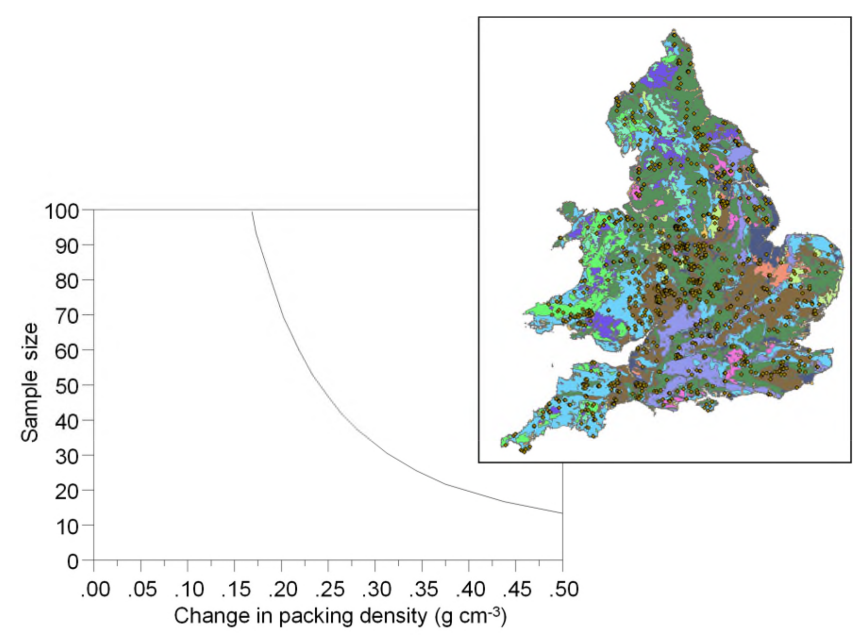

Figure 2. Power analysis on national soil packing density data based on land use by soil strata. The spatial distribution of the data points superimposed on the land use/soil classification is taken from Graves et al. (2011).
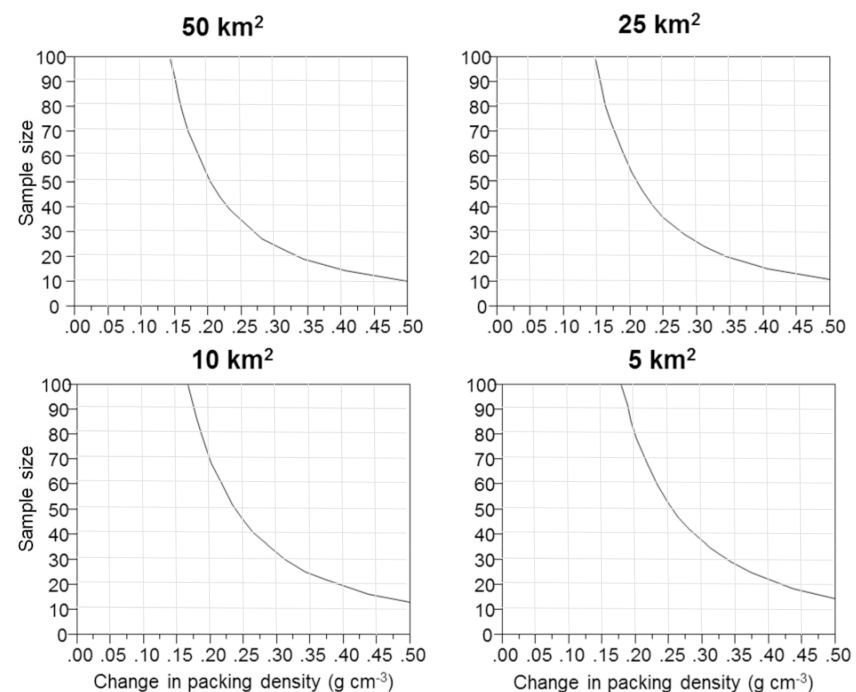

Figure 3. Power analysis using a model-based approach in which the variability was estimated given a particular block size using the variogram described in Methods S9. Soil water retention characteristics.

$50 \mathrm{~km}^{2}$ ) was determined (Fig. 3). The graphs suggest that as spatial area increases, the number of samples also needs to increase in order to determine change within a given size of spatial area. If other factors that contribute to spatial variability of PD (such as land use) are included, fewer samples are required.

\subsection{Soil water retention characteristics}

Soil water retention characteristics (SWRCs) encapsulate a number of important capacity-based physical SQIs, includ- ing plant available water capacity (PAWC), air capacity (AC), relative field capacity (RFC), macroporosity $(M)$, soil porosity (Reynolds et al., 2002, 2009) and the soil physical quality index, the Dexter " $S$ " value (Dexter, 2004a, b, c). Of these, PAWC, $M$ and the Dexter $S$ value are related to root growth and therefore directly to provisioning soil functions such as crop production. PAWC refers to the soil's capacity to store and provide water that is available for uptake by plant roots. $M$ represents the volume of macropores with an equivalent pore diameter $\geq 300 \mu \mathrm{m}$, indicating the capacity of the soil to drain excess water quickly and facilitate root growth (Reynolds et al., 2009). The Dexter $S$ value is a measure of the micro-porosity of the soil (Dexter, 2004c) and has been linked to a number of soil physical processes and soil quality indicators, including bulk density. It is also related to root growth in soil (Dexter, 2004a). Generally, the higher the value of $S$, the higher the soil physical quality. It is recommended that the $S$ value be used in combination with other capacity-based indicators. This is because, in some soils, values may be overestimated (e.g. sands with unimodal and narrow pore size distributions) (Reynolds et al., 2009).

The Dexter $S$ value and other capacity-based physical SQIs are related to pore volume and pore size distribution (Reynolds et al., 2009). They are derived from soil hydraulic behaviour and therefore are likely to be more sensitive to temporal and spatial changes in soil condition and soil quality compared to other less dynamic indicators which look solely at pore volume, such as bulk density (Dexter, 2004a; Merrington et al., 2006; Naderi-Boldaji and Keller, 2016). The optimum values for each of the relevant physical SQIs for the provisioning function are displayed in Table 2 and are assumed to represent a meaningful change in the physical SQI as changes of this magnitude are expected to affect root (and therefore crop) growth.

In order for the soil water retention characteristics SQI to be meaningful, it needs to be indicative of soil functions that operate at different spatial scales (i.e. laboratory to field to catchment). However, O'Connell et al. $(2004,2007)$ and Beven et al. (2008) discuss uncertainties and inconsistencies in the measurement of rainfall and flow data between years, which tend to dominate over the impacts of land use and management change on flow characteristics at the catchment scale over time. These include uncertainties in estimates of precipitation inputs to a catchment, uncertainty in measurements of stream discharges (particularly during flooding events), and the uncertainty in characterising land use/management patterns in space and time. Also, significant impacts at the local scale may not have significant impact at catchment scales, due to poor landscape connectivity (Rickson et al., 2012). As such, there are gaps in connecting soil hydrological processes and the physical properties that influence them at the larger scale, and this influences any sampling efforts.

In terms of sampling effort, the standard Soil Survey of England and Wales method for determining soil water reten- 
Table 2. Soil water retention characteristics indicators, optimum values and impacts on the provisioning soil function. Values for PAWC, M and RFC taken from Reynolds et al. (2009). Values for Dexter $S$ value taken from (Dexter, 2004a). $\theta_{\text {FC }}$ : volumetric moisture content at field capacity, occurring at 0.5 or $1 \mathrm{~m}$ pressure head; $\theta_{\text {sat }}$ : saturated moisture content at $0 \mathrm{~m}$ pressure head; $\theta_{\mathrm{PWP}}$ : moisture content at permanent wilting point, occurring at $150 \mathrm{~m}$ pressure head; $\theta_{\mathrm{m}}$ : porosity of the soil matrix occurring at $0.1 \mathrm{~m}$ pressure head.

\begin{tabular}{|c|c|c|c|}
\hline Indicator & Optimum values & \multicolumn{2}{|c|}{ Soil function (i.e. provisioning function: root growth) } \\
\hline $\begin{array}{l}\text { Plant available water } \\
\text { capacity (PAWC) }\end{array}$ & $\mathrm{PAWC} \geq 0.20$ & \multicolumn{2}{|c|}{$\begin{array}{l}\text { Maximal root growth and function } \\
\text { (will vary according to crop type and variety) }\end{array}$} \\
\hline$\left(\mathrm{PAWC}=\theta_{\mathrm{FC}}-\theta_{\mathrm{PWP}}\right)$ & $0.15 \geq \mathrm{PAWC} \leq 0.20$ & \multicolumn{2}{|l|}{ Good } \\
\hline$\left(\mathrm{vol} / \mathrm{vol} ; \mathrm{cm}^{3} \mathrm{~cm}^{-3}\right)$ & $0.10 \geq \mathrm{PAWC} \leq 0.15$ & \multicolumn{2}{|l|}{ Limited } \\
\hline & $\mathrm{PAWC} \leq 0.10$ & \multicolumn{2}{|c|}{ Poor for root development } \\
\hline Macroporosity $(M)$ & $M \geq 0.05-0.10$ & \multicolumn{2}{|l|}{ Optimal } \\
\hline$\left(M=\theta_{\mathrm{sat}}-\theta_{\mathrm{m}}\right)\left(\mathrm{cm}^{3} \mathrm{~cm}^{-3}\right)$ & $M \leq 0.04$ & \multicolumn{2}{|c|}{ Soils degraded by compaction } \\
\hline $\begin{array}{l}\text { Relative field } \\
\text { capacity (RFC) }\end{array}$ & $0.6 \leq \mathrm{RFC} \leq 0.7$ & \multicolumn{2}{|c|}{$\begin{array}{l}\text { Optimal balance between available } \\
\text { water and air capacity }\end{array}$} \\
\hline $\begin{array}{l}\text { (rain-fed agriculture and } \\
\text { mineral soils) } \\
\left(\mathrm{RFC}=\theta_{\mathrm{FC}} / \theta_{\text {sat }}\right)\end{array}$ & $\begin{array}{l}\mathrm{RFC} \leq 0.6 \\
\mathrm{RFC} \geq 0.7\end{array}$ & $\begin{array}{l}\text { Insufficient water - } \\
\text { droughtiness } \\
\text { Insufficient air - } \\
\text { waterlogging }\end{array}$ & $\begin{array}{l}\text { Potential reduction in microbial } \\
\text { activity, in particular microbial } \\
\text { production of nitrate }\end{array}$ \\
\hline Dexter $S$ value $\left(S_{\mathrm{g}}\right)$ & $S_{\mathrm{g}}<0.020$ & \multicolumn{2}{|c|}{ "Very poor" soil physical quality } \\
\hline & $0.020 \geq S_{\mathrm{g}} \leq 0.035$ & \multicolumn{2}{|c|}{ "Poor" soil physical quality } \\
\hline & $0.035 \geq S_{\mathrm{g}} \leq 0.050$ & \multicolumn{2}{|c|}{ "Good" soil physical quality } \\
\hline & $S_{\mathrm{g}} \geq 0.050$ & \multicolumn{2}{|c|}{ "Very good" soil physical quality } \\
\hline
\end{tabular}

tion characteristics is to collect three undisturbed soil samples per horizon in winter or spring, when the soil is near field capacity (Avery and Bascomb, 1982). This involves using a coring device that reduces compaction during sampling. The laboratory measurement of soil water retention characteristics can be lengthy and requires considerable effort. The process involves saturation of the soil samples, allowing soils to reach equilibration, determining bulk density and finally calculating the volumetric water content at different soil water suctions. For the current analysis, soil water retention curves were calculated from soil water retention data from the LandIS database (http://www.landis.org.uk/; see Table 1). The method used is shown in Methods S11 in the Supplement.

As an alternative, pedotransfer functions (PTFs) can be a proxy technique that can be used to derive these properties from simple to measure soil characteristics such as BD and soil carbon (C) (Matula et al., 2007; Mayr and Jarvis, 1999). Two types of PTFs were considered: the first represents a standard type PTF that is derived using multiple linear regressions (MLRs); the second is an extension of the MLR approach in which categorical data such as "soil series" and "land use" can be considered. Multiple additive regression splines (MARS) is a nonparametric regression technique that combines both regression splines and model selection meth- ods (Friedman, 1991). The general method used for the PTFs is described in Methods S10.

The results of the PTF were compared for fit (Table 3) and show a high level of agreement. MARS regression approaches tended to perform better than the standard regression approaches. The predicted values of the SWRC indicators were compared against the observed values calculated from the Land IS database. Again, there was good agreement amongst the PTFs (Fig. 4), and as such these approaches are feasible as a proxy for SWRC. It has been recommended that for a plot of 20 by $20 \mathrm{~m}, 25$ bulked samples would be required for the measurement of $\mathrm{BD}$ and organic $\mathrm{C}$ that are required for the input data for the PTFs (Rickson et al., 2012).

\subsection{Soil sealing}

Soil sealing refers to the impermeabilisation of soils resulting from natural factors (Pulido Moncada et al., 2014) and human activities (for example road construction) (Xiao et al., 2013). In the context of this work, soil sealing refers to the covering of soil surfaces by expanding urban infrastructure.

Soil sealing has been identified as one of the greatest threats to soil functions in the UK (Rawlins et al., 2013) and worldwide (García et al., 2014; Jie et al., 2002). The growth of these impervious areas is regarded as an indicator of land 
Table 3. Soil water retention characteristics: fit results from PTFs based on LandIS data (BD, texture (clay, silt and sand) and organic C content). $S_{\mathrm{V}}$ is related to $S_{\mathrm{g}}$ through the soil bulk density $\rho_{\mathrm{b}} S_{v=\rho_{b}} S_{\mathrm{g}}$.

\begin{tabular}{lrr|rr|rr|rr|rr|rr}
\hline & \multicolumn{2}{c}{$S_{\mathrm{V}}$} & \multicolumn{2}{c|}{$S_{\mathrm{g}}$} & $\begin{array}{c}\text { Relative field } \\
\text { capacity }\end{array}$ & \multicolumn{2}{c|}{$\begin{array}{c}\text { Drainable } \\
\text { porosity }\end{array}$} & $\begin{array}{c}\text { Plant available } \\
\text { water }\end{array}$ \\
\cline { 2 - 11 } & RSQ & conc $R$ & RSQ & conc $R$ & RSQ & conc $R$ & RSQ & conc $R$ & RSQ & conc $R$ \\
\hline Multiple regression & 0.56 & 0.73 & 0.82 & 0.85 & 0.61 & 0.78 & 0.53 & 0.65 & 0.58 & 0.72 \\
MARS & 0.72 & 0.75 & 0.87 & 0.9 & 0.73 & 0.85 & 0.71 & 0.08 & 0.68 & 0.82 \\
\hline
\end{tabular}

RSQ: $R^{2}$ statistic; conc $R$ : correlation coefficient.

(a)

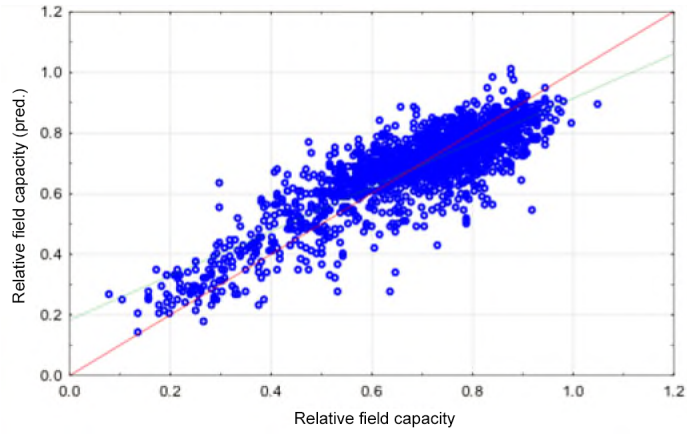

(b)

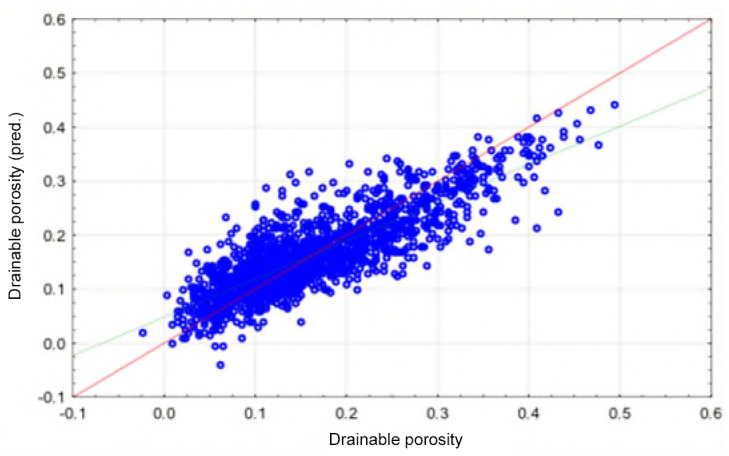

(c)

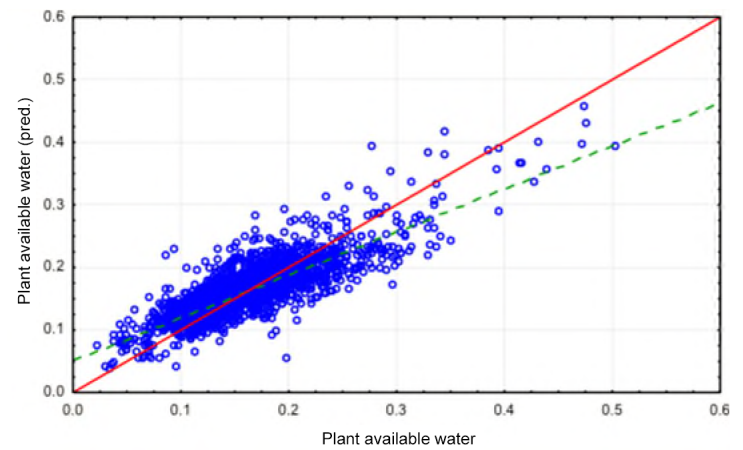

Figure 4. Biplots representing the predicted SQI versus observed SQI based on the MARS pedotransfer functions. (a) Relative field capacity. (b) Drainable porosity. (c) Plant available water. degradation (Munafò et al., 2013) as it results in interruptions to gaseous, water and energy exchanges in soils (for example water regulation); decreased biomass production; and increased concentrations of soil pollutants (Scalenghe and Marsan, 2009). Soil sealing also has a climatic impact by altering surface albedo and air temperature, and can impact on soil biogeochemical cycles (Gregory et al., 2015b; Zhao et al., 2012). In order to observe and assess changes in these soil functions, the change in the proportion of sealed surfaces must also be monitored.

There are a number of methods to evaluate soil sealing that have been used in the past, ranging from statistical analysis of national cadastral maps to aerial photo interpretation (Rickson et al., 2012). Currently, remote sensing techniques are favoured as they have a large spatial and temporal coverage, have improved certainty of measurements and also provide baseline data on the proportion of sealed soils within urban areas. The extent of the built environment can be estimated using a number of remote sensing techniques including high-resolution satellite imagery $(<1 \mathrm{~m}$ ground resolution) and aerial photography. Both these methods allow for the inclusion of narrow corridors such as roads and rail tracks, as well as providing accurate estimates of unsealed soil areas surrounding urban areas (i.e. green spaces). By integrating remote sensing with other, existing databases such as soil maps, even finer spatial resolutions can be achieved (Rickson et al., 2012).

In terms of measurement, the key indicators for soil sealing are (1) the absolute area of sealed soil (ha) and (2) the change/growth rate of area of sealed soil (ha $\mathrm{yr}^{-1}$, ha d $\mathrm{d}^{-1}$, $\%$ change to baseline). With the first indicator, the levels of soil sealing can depend on a number of factors including policy decisions, individual's choice and the degree of coverage (Meinel and Hernig, 2005) ranging from $100 \%$ sealed (roofs, concrete, asphalt) to $70 \%$ sealed (paving slabs with seep-able joints) to $50 \%$ sealed or less (green roofs, gravel, crushed stone, porous pavements). The measure of change/growth rate associated with the second indicator must also incorporate any de-sealing (or negative sealing) that would reduce the extent of sealed soil (for example installation of green roofs, porous block paving, porous tarmac and geotextiles used in car parks). This would require very high- 

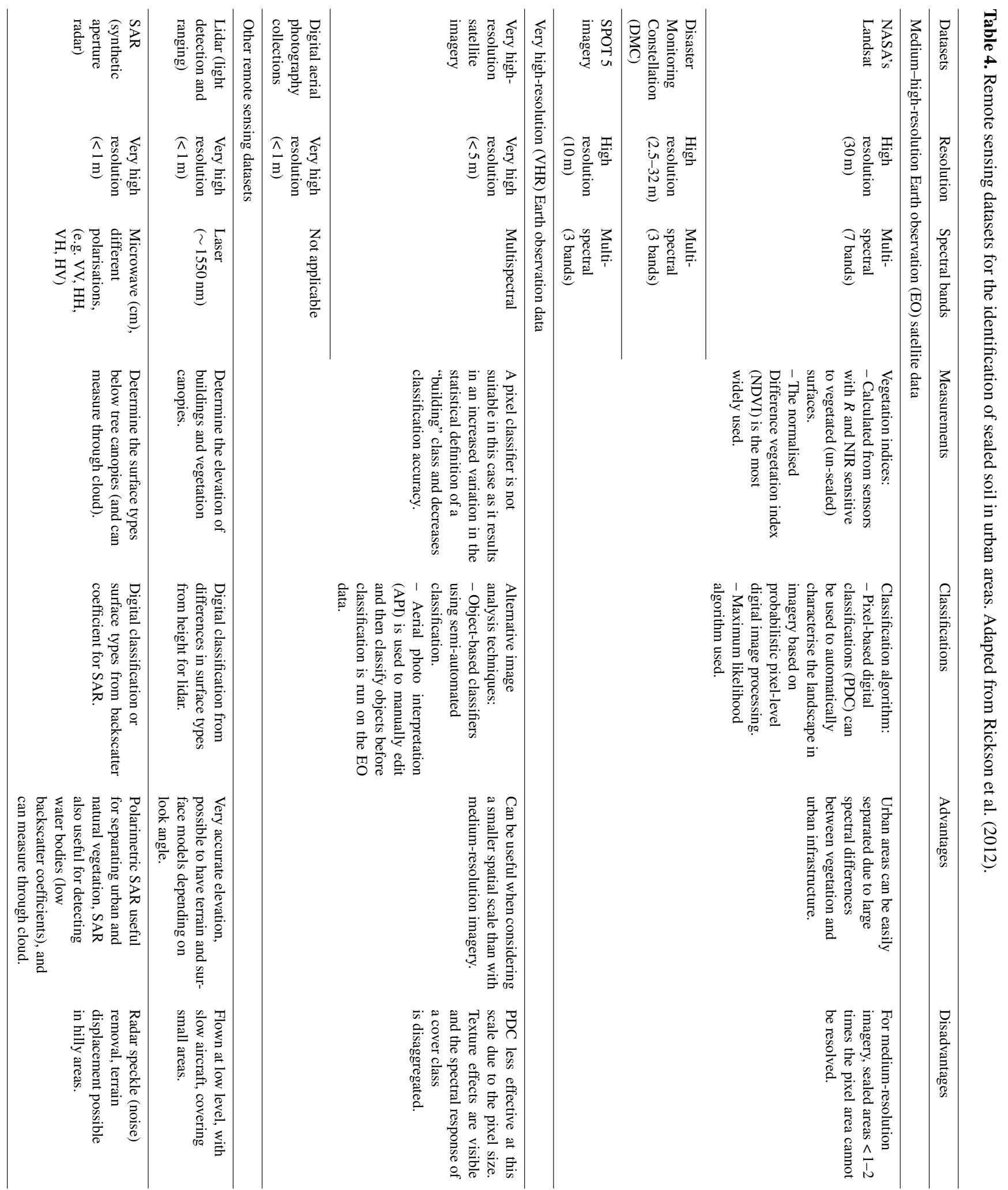
resolution $(<1 \mathrm{~m})$ monitoring data as the areas can be small and fragmented.

There are a number of earth observation data that can be used (Table 4) for identifying, classifying and monitoring soil sealing. They all have advantages, disadvantages and considerations for the user in terms of sampling/data analysis effort required. One of the most important considerations relates to spatial and temporal scale. The use of remotely sensed information allows population estimates to be made in the imaged area at the pixel resolution. As such there is usually a trade-off between the resolution and area that is covered. In terms of the spatial scale for urban areas, very high-resolution data $(<1 \mathrm{~m})$ are recommended to monitor smaller sealed and fragmented areas such as domestic driveways. This scale is also recommended for determining de-sealed surfaces which tend to be small scale.

Regarding appropriate temporal scales of measurement and monitoring, soil sealing in urban areas can occur on the timescale of months to years depending on what is being built. Furthermore, the capture of remote sensing data, in particular very high-resolution imagery usually occurs only every 3-5 years (Rickson et al., 2012) and therefore a monitoring schedule would have to fit around this. If medium- to high-spatial-resolution imagery is to be used, sampling could take place annually (data are collected more frequently and has a larger spatial coverage) (Rickson et al., 2012).

\subsection{General approach}

The multi-stage approach used in this study proved to be flexible, and whilst there was paucity in the data, it can be altered according to the needs of the end user/monitoring body/policy maker and what they want to get out of a soil monitoring programme. These diverse needs to be reflected in the priorities set in the logical sieve process, cost considerations, sample numbers and/or what constitutes meaningful change for that end use. In order to test for meaningful change in the selected indicators, spatial and temporal data are required to reflect the variability of each property (signal: noise ratio). However, in the examples given, recommendations for a sampling effort were based solely on the scientific literature. In this case, the evidence base was poor in terms of data that are meaningful (i.e. degree of change in the SQI that will affect soil processes and functions) and detectable (sample size required to detect the meaningful signal from the variability in the signal) (Rickson et al., 2012). In order to overcome this, further work is required to build up the evidence base in terms of spatial and temporal data on the key SQIs. Where other sampling issues were identified, suitable proxies or modelling functions were tested and proved to be effective in terms of how well they correlated with the standard measurements for the indicator and any time/labour issues associated with its measurement.

\section{Conclusions}

This study has demonstrated a multi-stage process that prioritises and analyses the suitability of physical SQIs for monitoring soil quality and function. In the first stage a logical sieve and alternative scenario approach were used to prioritise candidate physical SQIs from the literature. These were then assessed for uncertainty in their measurement, spatial variability, expected rate of change and impacts on soil processes and functions. Of the seven prioritised physical SQIs, three were selected here as case studies representing the varying degrees of analysis and modelling that could be applied depending on the evidence base.

By emphasising the current key soil functions related to current soil and environmental policy in the UK (i.e. provisioning and regulating functions), the prioritised SQIs can be related to soil processes, soil functions and consequent delivery of ecosystem goods and services. These are likely to shape any future soil and environmental policy in the UK, as well as efforts to develop soil monitoring programmes that aim to evaluate soil physical quality.

Data availability. Data used in this analysis pertains to the LandIS datasystem and can be accessed through www.LandIS.org.uk and has is recorded on data.gov.uk as NSRI-LANDIS-NATMAP1000.

\section{The Supplement related to this article is available online at https://doi.org/10.5194/se-8-1003-2017-supplement.}

Competing interests. The authors declare that they have no conflict of interest.

Acknowledgements. This research was funded by the UK Department of Environment, Food and Rural Affairs (DEFRA project number SP1611). Part of this work (T. G. Mercer's time) was conducted as part of the Fragments, Functions and Flows in Urban Ecosystem Services $\left(\mathrm{F}^{3} \mathrm{UES}\right.$ ) project (grant number NE/J015067/1) with support from the Biodiversity and Ecosystem Service Sustainability (BESS) programme. BESS is a six-year programme (2011-2017) funded by the UK Natural Environment Research Council (NERC) and the Biotechnology and Biological Sciences Research Council (BBSRC) as part of the UK's Living with Environmental Change (LWEC) programme. It was also conducted under BBSRC grant BB/M011860/1, which covered R. Corstanje's time and contributions to the paper. The views expressed are those of the authors and not necessarily those of DEFRA, NERC or BBSRC.

Edited by: Miriam Muñoz-Rojas

Reviewed by: Edoardo Costantini, Evgeny Abakumov, Fernando Pacheco, and two anonymous referees 


\section{References}

Arshad, M. and Coen, G.: Characterization of soil quality: Physical and chemical criteria, Am. J. Alternativ. Agr., 7, 25-31, https://doi.org/10.1017/S0889189300004410, 1992.

Asensio, V., Guala, S. D., Vega, F. A., and Covelo, E. F.: A soil quality index for reclaimed mine soils, Environ. Toxicol. Chem., 32, 2240-8, https://doi.org/10.1002/etc.2315, 2013.

Avery, B. W. and Bascomb, C. L.: Soil Survey Laboratory Methods. Soil Survey Technical Monograph No. 6, Harpenden, UK, 1982.

Beven, K., Young, P., Romanowicz, R., O'Connell, E., Ewen, J., O’Donnell, G., Holman, I., Posthumus, H., Morris, J., Hollis, J., Rose, S., Lamb, R., and Archer, D.: Analysis of historical data sets to look for impacts of land use and management change on flood generation, Defra RandD Final Report FD2120, 2008.

Bone, J., Head, M., Barraclough, D., Archer, M., Scheib, C., Flight, D., and Voulvoulis, N.: Soil quality assessment under emerging regulatory requirements, Environ. Int., 36, 609-22, https://doi.org/10.1016/j.envint.2010.04.010, 2010.

Breure, A. M., De Deyn, G. B., Dominati, E., Eglin, T., Hedlund, K., Van Orshoven, J., and Posthuma, L.: Ecosystem services: a useful concept for soil policy making, Current Opinion in Environmental Sustainability, 4, 578-585, https://doi.org/10.1016/j.cosust.2012.10.010, 2012.

Burger, J. A. and Kelting, D. L.:Using soil quality indicators to assess forest stand management, Forest Ecol. Manage., 122, 155166, https://doi.org/10.1016/S0378-1127(99)00039-0, 1999.

Morton, R. D., Rowland, C., Wood, C., Meek, L., Marston, G., Smith, G., Wadsworth, R., Simpson, I.: CEH: Land Cover Map 2007, https://doi.org/10.5285/1d78e01a-a9c1-4371-84821c1b57d9661f, 2011.

Costantini, E. A. C., Branquinho, C., Nunes, A., Schwilch, G., Stavi, I., Valdecantos, A., and Zucca, C.: Soil indicators to assess the effectiveness of restoration strategies in dryland ecosystems, Solid Earth, 7, 397-414, https://doi.org/10.5194/se-7-397-2016, 2016.

Costantini, E. A. C. and L'Abate, G.: The soil cultural heritage of Italy: Geodatabase, maps, and pedodiversity evaluation, Quatern. Int., 209, 142-153, https://doi.org/10.1016/j.quaint.2009.02.028, 2009.

Costanza, R., Wilson, M., Troy, A., Voinov, A., Liu, S., and D'Agostino, J.: The Value of New Jersey's Ecosystem Services and Natural Capital, New Jersey Department of Environmental Protection, 2006.

Dam, R. F., Mehdi, B. B., Burgess, M. S. E., Madramootoo, C. A., Mehuys, G. R., and Callum, I. R.: Soil bulk density and crop yield under eleven consecutive years of corn with different tillage and residue practices in a sandy loam soil in central Canada, Soil and Tillage Research, 84, 41-53, https://doi.org/10.1016/j.still.2004.08.006, 2005.

da Silva, A. P., Nadler, A., and Kay, B.: Factors contributing to temporal stability in spatial patterns of water content in the tillage zone, Soil and Tillage Research, 58, 207-218, https://doi.org/10.1016/S0167-1987(00)00169-0, 2001.

DEFRA: The natural choice: securing the value of nature, Natural Environment White Paper, UK Department for Environment Food and Rural Affairs (DEFRA), London, UK, https://www.gov.uk/government/uploads/system/uploads/ attachment_data/file/228842/8082.pdf (last access: 31 October 2016), 2011a.
DEFRA: Safeguarding our Soils, UK Department for Environment Food and Rural Affairs (DEFRA), London, UK, https://www.gov.uk/government/publications/ safeguarding-our-soils-a-strategy-for-england (last access: 31 October 2016), 2011b.

de la Rosa, D.: Soil quality evaluation and monitoring based on land evaluation, Land Degradation and Development, 16, 551-559, https://doi.org/10.1002/ldr.710, 2005.

Dexter, A. R.: Soil physical quality: Part I. Theory, effects of soil texture, density, and organic matter, and effects on root growth, Geoderma, 120, 201-214, https://doi.org/10.1016/j.geoderma.2003.09.004, 2004a.

Dexter, A. R.: Soil physical quality: Part II. Friability, tillage, tilth and hard-setting, Geoderma, 120, 215-225, https://doi.org/10.1016/j.geoderma.2003.09.005, 2004b.

Dexter, A. R.: Soil physical quality: Part III: Unsaturated hydraulic conductivity and general conclusions about S-theory, Geoderma, 120, 227-239, https://doi.org/10.1016/j.geoderma.2003.09.006, 2004c.

Ditzler, C. and Tugel, A.: Soil quality field tools: experiences of USDA-NRCS soil quality, Ahronomy Journal, 94, 33-38, 2002.

Doran, J. and Parkin, T.: Defining and assessing soil quality, in: Proceedings of a symposium on defining soil quality for a sustainable environment (Minneapolis 1992), edited by: Bezdicek, D. and Stewart, B., Soil Science Socity of America/American Society of Agronomy, Wisconsin, 3-21 1994.

Edmondson, J. L., Davies, Z. G., McCormack, S. A., Gaston, K. J., and Leake, J. R.: Are soils in urban ecosystems compacted? A citywide analysis, Biol. Lett.-UK, 23, 771-774, 2011.

European Commission: Thematic Strategy for Soil Protection [SEC(2006)620] [SEC(2006)1165], available at: http://eur-lex.europa.eu/legal-content/EN/TXT/?uri=celex\% 3A52006DC0231, 2006.

Friedman, J. H.: Multivariate Adaptive Regression Splines, Ann. Stat., 19, 1-67, 1991.

García, P., Pérez, M. E., and Guerra, A.: Using TM images to detect soil sealing change in Madrid (Spain), Geoderma, 214, 135-140, https://doi.org/10.1016/j.geoderma.2013.09.017, 2014.

Serrano, E. and Ruiz-Flaño, P.: Geodiversity : a theoretical and applied concept, Geogr. Helv., 62, 140-147, https://doi.org/10.5194/gh-62-140-2007, 2007.

Graves, A., Morris, J., Deeks, L. K., Rickson, J., Kibblewhite, M. G., Harris, J. A., and Farewell, T. S.: The Total Costs of Soils Degradation in England and Wales. UK Department for Environment Food and Rural Affairs (DEFRA), London, UK, http://sciencesearch.defra.gov.uk/Default.aspx? Menu=Menu $\&$ Module $=$ More $\&$ Location $=$ None $\&$ Completed $=$ 0\&ProjectID=16992, 2011.

Gregory, A. S., Ritz, K., McGrath, S. P., Quinton, J. N., Goulding, K. W. T., Jones, R. J. A., Harris, J. A., Bol, R., Wallace, P., Pilgrim, E. S., and Whitmore, A. P.: A review of the impacts of degradation threats on soil properties in the UK, Soil Use Manage., 31, 1-15, https://doi.org/10.1111/sum.12212, 2015a.

Gregory, A. S., Ritz, K., McGrath, S. P., Quinton, J. N., Goulding, K. W. T., Jones, R. J. A., Harris, J. A., Bol, R., Wallace, P., Pilgrim, E. S., and Whitmore, A. P.: A review of the impacts of degradation threats on soil properties in the UK, Soil Use Manage., 31, 1-15, https://doi.org/10.1111/sum.12212, 2015b. 
Huber, S., Prokop, G., Arrouays, D., Banko, G., Bispo, A., Jones, R. J. A., Kibblewhite, M. G., Lexer, W., Möller, A., Rickson, R. J., Shishkov, T., Stephens, M., Toth, G., Van den Akker, J. J. H., Varallyay, G., Verheijen, F. G. A., and Jones, A. R.: Environmental Assessment of Soil for Monitoring: Volume I Indicators and Criteria, EUR 23490 EN/1, Luxembourg, 2008.

Jie, C., Jing-zhang, C., Man-zhi, T., and Zi-tong, G.: Soil degradation: a global problem endangering sustainable development, J. Geogr. Sci., 12, 243-252, https://doi.org/10.1007/BF02837480, 2002.

Jónsson, J. O. G. and Davídsdóttir, B.: Classification and valuation of soil ecosystem services, Agr. Syst., 145, 24-38, 2016.

Jones, C. A.: Effect of Soil Texture on Critical Bulk Densities for Root Growth1, Soil Sci. Soc. Am. J., 47, 1208, https://doi.org/10.2136/sssaj1983.03615995004700060029x, 1983.

Jones, R. J., Spoor, G., and Thomasson, A.: Vulnerability of subsoils in Europe to compaction: a preliminary analysis, Soil and Tillage Research, 73, 131-143, https://doi.org/10.1016/S01671987(03)00106-5, 2003.

Karlen, D. and Stott, D.: A Framework for evaluating physical and chemical indicators of soil quality, in: Defining soil quality for a sustainable environment; Proceedings of a symposium, Doran, J., Leman, D., Bezdicek, D., and Stewart, B., Soil Science Society of America, Madison, Wisconsin, 53-72, 1994.

Loveland, P. and Thompson, T.: Identification and development of a set of national indicators for soil quality, Environment Agency, RandD Project Report P5-053/PR/02, 2002.

Masto, R. E., Sheik, S., Nehru, G., Selvi, V. A., George, J., and Ram, L. C.: Assessment of environmental soil quality around Sonepur Bazari mine of Raniganj coalfield, India, Solid Earth, 6, 811821, https://doi.org/10.5194/se-6-811-2015, 2015.

Matula, S., Mojrová, M., and Špongrová, K.: Estimation of the soil water retention curve (SWRC) using pedotransfer functions (PTFs), Soil Water Res., 2, 113-122, 2007.

Mayr, T. and Jarvis, N.: Pedotransfer functions to estimate soil water retention parameters for a modified Brooks-Corey type model, Geoderma, 91, 1-9, https://doi.org/10.1016/S00167061(98)00129-3, 1999.

Meinel, G. and Hernig, A.: Survey of soil sealing on the basis of the ATKIS basic DLM - feasibilities and limits, Urban Planning and Spatial Development and Impacts of ICT on Physical Space, 10th International Conference of Information and Communications Technologies (ICT), 2005.

Merrington, G., Fishwick, S., Barraclough, D., Morris, J., Preedy, N., Boucard, T., Reeve, M., Smith, P., and Fang, C.: The development and use of soil quality indicators for assessing the role of soil in environmental interactions, Environment Agency Science Report SC030265, Bristol, UK, 2006.

Millennium Ecosystem Assessment: A report of the Millennium Ecosystem Assessment, 2005.

Mouazen, A. M. and Ramon, H.: Development of on-line measurement system of bulk density based on on-line measured draught, depth and soil moisture content, Soil and Tillage Research, 86, 218-229, https://doi.org/10.1016/j.still.2005.02.026, 2006.

Munafò, M., Salvati, L., and Zitti, M.: Estimating soil sealing rate at national level - Italy as a case study, Ecol. Indic., 26, 137-140, https://doi.org/10.1016/j.ecolind.2012.11.001, 2013.
Naderi-Boldaji, M. and Keller, T.: Degree of soil compactness is highly correlated with the soil physical quality index $S$, Soil and Tillage Research, 159, 41-46, https://doi.org/10.1016/j.still.2016.01.010, 2016.

O’Connell, P. E., Beven, K. J., Carney, J. N., Clements, R. O., Ewen, J., Fowler, H., Harris, G. L., Hollis, J., O'Donnell, G. M., Packman, J. C., Parkin, A., Quinn, P. F., Rose, S. C., Shepherd, M., and Tellier, S.: Review of impacts of rural land management on flood generation, Impact Study Report, Defra RandD Technical Report FD2114/TR, 2004.

O'Connell, P. E., Ewen, J., O'Donnell, G., and Quinn, P.: Is there a link between agricultural land-use management and flooding?, Hydrol. Earth Syst. Sci., 11, 96-107, https://doi.org/10.5194/hess-11-96-2007, 2007.

Price, P. N., Chambers, B., and Whittingham, M.: Characterisation of Soil Structural Degradation Under Grassland and Development of Measures to Ameliorate its Impact on Biodiversity and Other Soil Functions, BD5001, 2012.

Pulido Moncada, M., Gabriels, D., Lobo, D., De Beuf, K., Figueroa, R., and Cornelis, W. M.: A comparison of methods to assess susceptibility to soil sealing, Geoderma, 226, 397-404, https://doi.org/10.1016/j.geoderma.2014.03.014, 2014.

Pulleman, M., Creamer, R., Hamer, U., Helder, J., Pelosi, C., Pérès, G., and Rutgers, M.: Soil biodiversity, biological indicators and soil ecosystem services - an overview of European approaches, Curr. Opin. Environ. Sustain., 4, 529-538, https://doi.org/10.1016/j.cosust.2012.10.009, 2012.

Rawlins, B. G., Harris, J., Price, S., and Bartlett, M.: A review of climate change impacts on urban soil functions with examples and policy insights from England, UK, Soil Use Manage., 31, 46-61, https://doi.org/10.1111/sum.12079, 2013.

Reynolds, W., Bowman, B., Drury, C., Tan, C., and Lu, X.: Indicators of good soil physical quality: density and storage parameters, Geoderma, 110, 131-146, https://doi.org/10.1016/S00167061(02)00228-8, 2002.

Reynolds, W. D., Drury, C. F., Tan, C. S., Fox, C. A., and Yang, X. M.: Use of indicators and pore volume-function characteristics to quantify soil physical quality, Geoderma, 152, 252-263, https://doi.org/10.1016/j.geoderma.2009.06.009, 2009.

Rickson, R., Deeks, L., Corstanje, R., Newell-Price, P., Kibblewhite, M., Chambers, B., Bellamy, P., Holman, I., James, I., Jones, R., Kechavarsi, C., Mouazen, A., Ritz, K., and Waine, T.: Indicators of soil quality - physical properties (SP1611), Final Report to DEFRA, available at: http://randd.defra.gov.uk/ Document.aspx? ?ocument=11182_SP1611finalreport.pdf (last access: 24 April 2017), 2012.

Ritz, K., Black, H. I. J., Campbell, C. D., Harris, J. A., and Wood, C.: Selecting biological indicators for monitoring soils: A framework for balancing scientific and technical opinion to assist policy development, Ecol. Indic., 9, 1212-1221, https://doi.org/10.1016/j.ecolind.2009.02.009, 2009.

Robinson, D. A., Hockley, N., Cooper, D. M., Emmett, B. A., Keith, A. M., Lebron, I., Reynolds, B., Tipping, E., Tye, A. M., Watts, C. W., Whalley, W. R., Black, H. I. J., Warren, G. P., and Robinson, J. S.: Natural capital and ecosystem services, developing an appropriate soils framework as a basis for valuation, Soil Biol. Biochem., 57, 1023-1033, https://doi.org/10.1016/j.soilbio.2012.09.008, 2013. 
Scalenghe, R. and Marsan, F. A.: The anthropogenic sealing of soils in urban areas, Landscape Urban Plan., 90, 1-10, https://doi.org/10.1016/j.landurbplan.2008.10.011, 2009.

Schipper, L. A. and Sparling, G. P.: Performance of Soil Condition Indicators Across Taxonomic Groups and Land Uses, Soil Sci. Soc. Am. J., 64, 300-311, https://doi.org/10.2136/sssaj2000.641300x, 2000.

Schoenholtz, S., Miegroet, H. V., and Burger, J.: A review of chemical and physical properties as indicators of forest soil quality: challenges and opportunities, Forest Ecol. Manag., 138, 335356, https://doi.org/10.1016/S0378-1127(00)00423-0, 2000.

Seybold, C., Mausbach, M., Karlen, D., and Rogers, H.: Quantification of soil quality, in: Soil processes and the carbon cycle, edited by: Lal, R. and Stewart, B., CRC Press, USA, 1998.

Sojka, R. and Upchurch, D.: Reservations regarding the soil quality concept, Soil Sci. Soc. Am. J., 63, 139-1054, 1999.
UNESCO: United Nations Educational, Scientific and Cultural Organization, UNESCO Global Geoparks: Celebrating Earth Heritage, Sustaining local Communities, Paris, France, 1-20, http: //unesdoc.unesco.org/images/0024/002436/243650e.pdf, 2016.

Xiao, R., Su, S., Zhang, Z., Qi, J., Jiang, D., and Wu, J.: Dynamics of soil sealing and soil landscape patterns under rapid urbanization, Catena, 109, 1-12, https://doi.org/10.1016/j.catena.2013.05.004, 2013.

Zhao, D., Li, F., Wang, R., Yang, Q., and Ni, H.: Effect of soil sealing on the microbial biomass, $\mathrm{N}$ transformation and related enzyme activities at various depths of soils in urban area of Beijing, China, J. Soil. Sediment., 12, 519-530, https://doi.org/10.1007/s11368-012-0472-6, 2012. 